\title{
JECH
}

\section{The impact of a newly designed resilience-enhancing programme on parent- and teacher-perceived resilience environment among Health Promoting Schools in Hong Kong}

M C S Wong, J Sun, A Lee, D Stewart, F F K Cheng, W Kan and M Ho

J Epidemiol Community Health 2009;63;209-214; originally published online 23 Sep 2008;

doi:10.1136/jech.2008.074260

Updated information and services can be found at:

http://jech.bmj.com/cgi/content/full/63/3/209

These include:

Data supplement

"web only appendix"

http://jech.bmj.com/cgi/content/full/jech.2008.074260/DC1

References This article cites 23 articles, 3 of which can be accessed free at:

http://jech.bmj.com/cgi/content/full/63/3/209\#BIBL

Rapid responses You can respond to this article at:

http://jech.bmj.com/cgi/eletter-submit/63/3/209

Email alerting Receive free email alerts when new articles cite this article - sign up in the box at service the top right corner of the article

Notes

To order reprints of this article go to:

http://journals.bmj.com/cgi/reprintform

To subscribe to Journal of Epidemiology and Community Health go to:

http:/journals.bmj.com/subscriptions/ 


\title{
The impact of a newly designed resilience-enhancing programme on parent- and teacher-perceived resilience environment among Health Promoting Schools in Hong Kong
}

\author{
M C S Wong, ${ }^{1,3}$ J Sun, ${ }^{2}$ A Lee, ${ }^{1,3}$ D Stewart, ${ }^{2}$ F F K Cheng, ${ }^{1}$ W Kan, ${ }^{1}$ M Ho ${ }^{1}$
}

\begin{abstract}
- Additional tables 3-6 are published online only at http:// jech.bmj.com/supplemental

${ }^{1}$ Faculty of Medicine, Chinese University of Hong Kong;

${ }^{2}$ School of Public Health, Griffith University, Australia; ${ }^{3}$ Hong Kong Health Education and Health Promotion Foundation
\end{abstract}

Correspondence to: Professor M C S Wong, 4/F, School of Public Health, Prince of Wales Hospital, Shatin, NT, Hong Kong SAR;

wong martin@cuhk.edu.hk

Accepted 8 September 2008 Published Online First

23 September 2008

\begin{abstract}
Background: The Health Promoting School (HPS) approach provides a strong foundation to improve students' overall health, including psychological wellbeing, which has its roots in resilience. The present study evaluates the effectiveness of a resilience-enhancing programme, building on the concept of HPS among a Chinese population.
\end{abstract}

Methodology: All mainstream schools in a socially disadvantaged region of Hong Kong were eligible, and stratified random sampling was used to recruit both HPS as intervention schools and non-HPS as control schools. The participants included teachers and parents of grade 3 and 5 primary and grade 1 secondary school students (aged 8, 10 and 12 respectively). Validated surveys were used to assess resilience scores in both groups of schools before and after a series of resilience-enhancing activities in HPS, and ANOVA was used to compare the score changes between the two groups.

Results: Five primary and four secondary HPS and four primary and four secondary non-HPS were recruited, involving 4918 parents and 602 teachers. Among primary and secondary parents, the HPS group did not report a higher score than the non-HPS group. Among secondary teachers, the HPS group showed significantly higher scores than the non-HPS group ( $p=0.023$ to $<0.001$ ) Conclusion: The present study is the first to demonstrate the positive synergistic effect of a newly designed resilience-enhancing intervention programme, building on the concept of HPS in schools among secondary teachers in Hong Kong. It was suggested that future initiatives may involve parent networking and school-family collaboration in fostering an even more resilient school environment.

The 21st century poses the greatest challenge to the young generation in developed countries with globalisation and rapid urbanisation leading to marginalisation and inequalities in health. Youth health surveys in 1999, 2001 and 2003 revealed a substantially high proportion of emotionally disturbed young people in Hong Kong, with over 10\% of young people suffering from emotional problems that interfere with their daily activities and also from suicidal ideas. ${ }^{1-3}$ Poor mental health was found to be a serious health concern in Chinese youths both in urban and rural areas. ${ }^{4}$ Emotional and social health are considered at the heart of school health promotion and many frameworks such as "emotional literacy", "conflict resolution", "problem solving", "social competency" and "community building" have all been used with some success. ${ }^{5}$ However, none of those frameworks are as comprehensive, as adaptable as Health Promoting School (HPS). ${ }^{5}{ }^{6}$ The concept of Health Promoting School (HPS), initiated by the WHO, moves beyond individual behavioural change to consider organisational structure change such as improving a school's physical and social environment, its curricula, teaching and learning methods. $^{78}$ The Hong Kong Healthy School Award (HKHSA) scheme was first launched in 2001 with the main objective to enhance positive healthy behaviour of students using a school-based approach, and the scheme has been implemented successfully with comprehensive guidelines and systems of school evaluation. ${ }^{8} 9$ Positive outcomes, especially in the areas of emotional health and social behaviours, have been well demonstrated among schools adopting this approach. ${ }^{10}$

Recent theoretical developments in mental health promotion suggest that psychosocial wellbeing has its roots in "resilience". ${ }^{11}$ This refers to the capacity of individuals, schools, families and communities to cope successfully with everyday challenges including life transitions, times of cumulative stress and significant adversity or risk. ${ }^{12}$ The foundations of resilience in young people include individual, family and school factors, and a critical factor in the development and strengthening of resilience involves the building of "connectedness". ${ }^{13}$ Resilient children have great strength crucial to maintenance and future development of psychosocial health, ${ }^{14}$ including higher self-esteem, clear goals and aspirations, respect for self and others, and the capacity to solve problems and seek out mentoring adult relationships. ${ }^{15} 16$ The resilience trait also underlies the capacity for positive emotional engagement in the context of stress, ${ }^{17}$ and promotion of resiliency programmes during early school years could prevent future emotional problems. ${ }^{18}$

Two key areas of the HKHSA scheme, namely social environment and community relationship, have covered the essential features needed to promote and build resilience within the school communities. $^{8919}$ The positive outcomes of HKHSA and resiliency programmes in mental health promotion should lead to further study in examining the synergistic effect of resilience programme building on the concept of HPS among Chinese students in Hong Kong.

As a previous study in Hong Kong has shown that the school environment is an influential factor 
on the lifestyle behaviour of students, ${ }^{20}$ we tested the hypotheses that creating a more resilient school environment would bring forth positive psychosocial outcomes as perceived by the major school stakeholders.

This study aims to evaluate the effectiveness of a newly designed resilience-enhancing programme, building on the concept of HPS in promoting resilience scores among parents and teachers in a group of schools that have joined HKHSA (HPS group), using a group of schools that have not adopted the HPS approach (non-HPS group) as a control.

\section{METHODS}

\section{Study design}

A prospective intervention study design was used in the study. The programme targeted the New Territory West (NTW) region of Hong Kong, which is relatively socially disadvantaged and has a higher proportion of emotional health problems. ${ }^{4} 21$ All mainstream schools in this region were eligible for the study. Schools in the Hong Kong Healthy School Award (HKHSA) scheme (the Health Promoting School [HPS] group) were targeted for intervention, and those that were not in the scheme (the non-HPS group) were used as controls. The resilience-promoting programme lasted for 4 months from October 2005 to January 2006 in intervention schools, and assessments were conducted before and 8 months after the programme in both intervention and control schools. Measurements were conducted using a well-validated set of survey instruments. ${ }^{22}$

\section{Subjects}

Invitation letters in lots of tens were sent to all eligible schools, and schools were randomly selected for both HPS and non-HPS groups during the commencement date of the programme, namely October 2005. Four primary and four secondary schools were targeted in each of the intervention and control groups by simple random sampling. However, the total number of schools participating in the study were four primary schools as the intervention group and five primary schools as a control group; with four secondary schools in each of the intervention and control groups. The parents and teachers of all primary grade 3 and grade 5 students (aged 8 and 10) and secondary grade 1 students (aged 12) of recruited schools were invited to complete the surveys, as well as participate in the interactive workshops.

\section{Intervention}

A newly designed, 4-month intervention programme was implemented with the HPS group in October 2005 until January 2006, with the non-HPS group receiving no intervention. The programme consists of two components: a 2-hour indepth discussion, started in October 2005, with each teacher-incharge of all HPS for potential resilience-enhancing activities in the forthcoming academic year, and interactive workshops with parents (November 2005) and teachers (December 2005) conducted by an experienced social worker (table 1). Measures were taken to ensure that a pre-intervention assessment took place before the formal intervention programme. In each of the participating schools, a small committee was formed or assigned to work closely with the Project Coordinator to coordinate the project, liaise with parents and other school members, and monitor and evaluate the progress. This programme aimed to consolidate a caring and supportive social environment in the schools and establish strong community partnerships according to the principles of HPS. The intervention schools were designed to have an enhanced commitment, experience and skills in health promotion and health education. The Project presented students, staff, parents and community members with a "Capability-Building Framework for Promoting Resiliency", to address the challenges of: under-achievement, poor socialemotional well-being, and capability-building in the community, school, home, and student contexts.

\section{Research hypotheses}

It was hypothesised that the intervention programme could produce the following positive changes:

1. The participating schools would develop more positive adult and peer social networks and greater feelings of connectedness.

2. The schools would develop a supportive physical and social environment, conducive to positive development for students, good school-community/family relations, and also showing features of shared decision-making and planning.

3. Parents would perceive their students to be more likely to have increased resilience related behaviour, such as selfesteem, empathy, help-seeking, goals and aspiration, and communication and cooperation.

\section{Evaluation methods}

The baseline evaluation was conducted in November 2005, and the post-intervention evaluation from June to July 2006.

The parent survey consists of 69 questions and results were reported in 13 dimensions (including three sub-dimensions). The Parents/Caregivers Support Scale comprised items relating to parents' perception of school environment, family functioning, and social support for family. The teacher survey consists of 72 questions and results were reported in 10 dimensions. It assesses the performance of schools in its policies, partnership and work connection related to resilience, as well as the social environment and community relationship. Both surveys consist of a five-point Likert scale, in which one indicates "strongly disagree" and five indicates "strongly agree". The parent and teachers' surveys have high reliability. The questionnaires were pilot-tested, translated and validated in Hong Kong Chinese populations. ${ }^{21}$

The intervention workshop was assessed by process evaluation using questionnaires designed by a professional in psychology with face-validity assessed by two independent experts in Public Health. A post-workshop survey was immediately administered for all the participants after the last session of the workshop, using a Likert scale with one representing "strongly disagree" and five representing "strongly agree". The surveys enquired about participant-perceived effectiveness of the workshops for resilience building, efficiency of resilience-linked knowledge imparting, ability of the workshops to facilitate learning principles, effectiveness in strengthening resilience skills, and self-perception of importance of using a parent-teacher collaborative approach to implement effective strategic resilience programmes.

\section{Main outcome measures}

All data were entered into the Statistical Package for Social Sciences (SPSS) version 13.0 (Chicago). The mean resilience scores before and after the programme were reported. The changes in scores, as measured by the surveys for parents and teachers, were compared between control and intervention schools stratified for primary and secondary schools respectively. Time (time 1 and time 2 ) $\times$ group (intervention vs 
Table 1 The Resilience-Enhancing Intervention Programme

\begin{tabular}{|c|c|}
\hline Interactive workshops for parents and teachers & In-depth discussion with teacher-in-charge for planning resilience-enhancing activities \\
\hline Objectives & Objectives \\
\hline $\begin{array}{l}\text { To equip teachers and parents with skills and competency in promoting } \\
\text { resilience and mental health }\end{array}$ & $\begin{array}{l}\text { To help schools to identify their needs and priorities for action; plan for activities to create an environment } \\
\text { of value and mutual respect }\end{array}$ \\
\hline Format & Format \\
\hline $\begin{array}{l}\text { Four weekly } 3 \text {-hour interactive sessions, sharing the concept of } \\
\text { resilience, stress management, effective communication, conflict } \\
\text { management, problem-solving and goal-setting }\end{array}$ & $\begin{array}{l}\text { A 1-hour session discussion with teachers in each school, planning school activities, and development of a } \\
\text { system to promote a friendly and caring environment and to facilitate students with special needs }\end{array}$ \\
\hline Responsible professional & Responsible professional \\
\hline A social worker well trained in psychology & A social worker well trained in psychology \\
\hline Major topics covered & Major topics covered \\
\hline $\begin{array}{l}\text { School Culture, Classroom Teaching Learning, Student Social- } \\
\text { Emotional Learning Curriculum, Student Mentoring, Parent Education, } \\
\text { Teacher Capability Building, and Community Involvement }\end{array}$ & $\begin{array}{l}\text { To facilitate family and community involvement in school activities to promote emotional health and build } \\
\text { resilience; to facilitate the schools to be more proactive in linking with other schools and local community }\end{array}$ \\
\hline Specific topics & Specific topics \\
\hline $\begin{array}{l}\text { Skills necessary to stay calm and to stop getting extremely angry, } \\
\text { depressed or worried when something "bad" happens }\end{array}$ & (1) Resiliency building for students \\
\hline $\begin{array}{l}\text { Skill in being able to distinguish between one's negative/irrational and } \\
\text { positive/rational thoughts, and being able to generate positive, rational } \\
\text { thoughts in adverse circumstances }\end{array}$ & $\begin{array}{l}\text { "Buddies" (peer support) system enabling the older children to experience their growing competencies as } \\
\text { well as the pleasure of being genuinely helpful to the younger children. The younger children, on the other } \\
\text { hand, would develop closer relationships with the older ones and experience models of helpfulness }\end{array}$ \\
\hline $\begin{array}{l}\text { Skills in being able to regulate the intensity of one's feelings including } \\
\text { the use of a variety of coping skills }\end{array}$ & (2) Parents' support group: \\
\hline $\begin{array}{l}\text { The five foundations for success and well-being (Confidence, } \\
\text { Persistence, Organisation, Getting Along, Emotional Resilience) } \\
\text { including self-awareness of strengths and weaknesses }\end{array}$ & $\begin{array}{l}\text { Schools advised to set up a parents' support group so that parents can share information about parenting } \\
\text { school issues and other health-related issues. The support group is expected to have a meeting every } \\
\text { month to facilitate communication within the group and with school }\end{array}$ \\
\hline \multirow{4}{*}{$\begin{array}{l}\text { Awareness and use of the } 12 \text { positive Habits of the Mind (e.g. } \\
\text { Accepting Myself, Working Tough, Tolerance of Others), which support } \\
\text { the five foundations of success and well-being }\end{array}$} & (3). Parent-child activities \\
\hline & $\begin{array}{l}\text { School advised to organise parent-child activities like community services, health promotion day, adventure } \\
\text { training, school cleansing day, fitting in their own needs and school schedule }\end{array}$ \\
\hline & (4). School network \\
\hline & $\begin{array}{l}\text { Set up to share good practice and to facilitate a proactive linkage amongst the participating schools and } \\
\text { also the local community agencies }\end{array}$ \\
\hline
\end{tabular}

control) interaction was analysed using ANOVA (Analysis of Variance) to examine the intervention effect. P values of $<0.05$ for all subscales of parents and staff survey were considered statistically significant.

\section{RESULTS}

The participant control schools included four primary and four secondary non-Health Promoting Schools (non-HPS), whereas the intervention arm consisted of five primary and four secondary HPS schools. In both groups of schools, in general, the primary school students were from two grades corresponding to 8 and 10 year olds, respectively, and those from secondary schools were from one grade of 12 year olds. The study involved 4918 parents and 602 teachers from the 17 schools recruited in the New Territory West region. There were marked differences in the numbers of participating teachers before and after the programme, mainly due to staff changes during the academic year; yet survey administrations were targeted to all parents and teachers at both control and intervention schools. The response rates ranged from $34.7 \%$ to $87.6 \%$, with the lowest response rate $(34.7 \%)$ among primary school teachers in the non-HPS before intervention. The distribution is shown in table 2 .

\section{Process evaluation of workshops}

The workshops were well perceived, as a high proportion of participants agreed that the objectives of the workshop were achieved. The attendance rates for both teachers and parents were $100 \%$. Approximately $93.3 \%$ of the participants "strongly agree" or "agree" that the interactive workshop would help to build resilience for their children or students. One-hundred per cent "strongly agree" or "agree" that the workshops were effective in imparting relevant knowledge, facilitating learning of principles and skills in strengthening resilience, and highlighted the importance of a parent-teacher collaborative approach in implementing an effective strategic resilience programme.

\section{Outcome evaluation of whole programme \\ Primary school parents}

The control primary school parents had positive changes in eight dimensions before and after the intervention, but none were statistically significant. The intervention primary school parents showed positive changes in all dimensions, with the exceptions being "school pressure" and "view community as a source of support and dimension". "School goals and objectives" was found to be statistically significant $(p=0.035)$ (table 3, online).

\section{Secondary school parents}

Both the control and intervention secondary school parents showed negative changes in the sub-dimension "school pressure", with positive changes in other dimensions. None of the respective changes comparing the control and intervention schools were statistically significant (table 4, online).

\section{Primary school teachers}

No difference exists between the changes of the control and intervention schools on all dimensions compared (table 5, online).

\section{Secondary school teachers}

All control secondary school teachers showed negative changes in all the constructs (except "physical environment") before and after intervention, whereas all intervention secondary school 
Table 2 Participant characteristics

\begin{tabular}{|c|c|c|c|c|}
\hline & Primary control schools & Primary intervention schools & Secondary control schools & Secondary intervention schools \\
\hline \multicolumn{5}{|l|}{ (II) Parents } \\
\hline \multicolumn{5}{|l|}{ Pre-intervention } \\
\hline Number & 898 & 564 & 542 & 409 \\
\hline \multicolumn{5}{|l|}{ Post-intervention } \\
\hline Number & 705 & 634 & 623 & 543 \\
\hline Response rate (\%) & 60.0 & 62.5 & 87.6 & 66.4 \\
\hline \multicolumn{5}{|l|}{ (III) Teachers } \\
\hline \multicolumn{5}{|l|}{ Pre-intervention } \\
\hline Number & 59 & 74 & 99 & 25 \\
\hline Response rate (\%) & 34.7 & 46.8 & 41.1 & 62.5 \\
\hline \multicolumn{5}{|l|}{ Post-intervention } \\
\hline
\end{tabular}

Intervention schools refer to health promoting schools (HPS) that received the resilience-enhancing intervention programme, and control schools were non-HPS that did not receive any intervention.

teachers showed positive changes with the magnitude in all dimensions ranging from 0.20 to 0.60 , with statistical significance except for "work connection" ( $p=0.023$ to $<0.001$ ) (table 6, online).

\section{DISCUSSION}

The process evaluation of the interactive workshops was highly encouraging and the parents felt strongly empowered in the training process. In addition, the present study has demonstrated a positive impact of this newly designed programme among secondary school teachers in the majority of resilience dimensions, as reflected by the significant score changes in the intervention group.

The effectiveness of the Health Promoting School (HPS) approach in building social capital, a fundamental factor in supporting school climates and school bonding, has been recently recognised. ${ }^{23}$ Among resilience-enhancing interventions for young adolescents is the Penn Resiliency Program (PRP) developed in Philadelphia, and the results of school-based preventive programmes targeted towards psychosocial health were mixed. ${ }^{24}$ Apart from some positive evaluation outcomes of PRP on psychosocial well-being, ${ }^{25-27}$ resilience studies have been conducted and evaluated among Western populations and results have been inconclusive. There have been few reports on the effectiveness of resilience programmes for Chinese populations. ${ }^{28}$ This study is the first newly designed intervention programme, tailored for Chinese populations, which demonstrates a significant impact in strengthening school resilience among secondary school teachers from an HPS group.

Parents and primary school teachers did not report significant changes in the present programme, except primary school parents had a better understanding of the goals and objectives of the school. This is not unexpected, as not all teachers and parents were directly involved in this intervention, except as subjects, and parents were involved only in interactive workshops where their influence on other school stakeholders requires considerable networking and communication as a prerequisite. These anticipated changes in culture and ethos in social environment and community relationship simply require more time for solid establishment. However, parents appear to have a better understanding of the schools in the intervention group. Time is another factor that is required for any schoolbased health promotion programme to be effective. ${ }^{29}$ Teachers are in a more advantageous position to influence not only students and parents but also directly influence the school curriculum and other resilience-related activities and initiatives. Hence, they are very suitable professionals to act as "entrypoint" influencers where resilience programs could be implemented.

In addition, teachers or parents may perceive "resilience" to be a rather advanced topic for primary schoolchildren well before they enter their adolescent stages. If teachers can act as expressive role models, this would be perceived as supportive to students. When compared to secondary schools, the scale of psychosocial problems is also considerably less serious among primary school students, and, thus, more incentives may be placed on promoting other aspects of health.

An important factor could account for the positive changes in teachers' perception of school ethos in secondary schools not observed in primary schools. It is well recognised that the acquisition of resilience competence commences during students' transition from emerging adulthood to young adulthood, ${ }^{29}$ a developmental stage too early for primary school students. The secondary school teachers, therefore, handle students differently. For adolescents, teachers need to create the school ethos and culture to help them with resilience. Hence, this programme demonstrates significant changes amongst secondary school teachers.

The limitations of this study should be mentioned. It is challenging to argue whether the positive changes were due to the resilience programme components, or simply attributed to the HPS approach already embodied in the intervention schools. It is, however, more likely that the reported changes are truly due to the present resilience programme, as analysis of baseline evaluation comparing HPS and non-HPS schools among secondary school teachers has revealed no difference in many aspects of resilience dimensions, including "feeling of trust and safety" ( $p=0.55)$, "proactivity in social context" ( $p=0.44)$ and "work connection" $(p=0.095)$. Also, there was a significant difference in the number of teachers before and after the programme, which does not allow for paired 
comparisons. Therefore, statistical analysis of the two samples independently at different observed periods could bring forth biases.

In addition, teacher and parent connections between HPS and non-HPS in the intervention period might induce contamination. However, this phenomenon would bias the result towards the null hypothesis only. Also, the slightly low response rates of both teachers and parents ranged from $34.7 \%$ to $87.6 \%$, particularly among teachers in control schools. School teachers and parents might not have strong incentives to complete surveys, especially when there are currently many surveys sent to schools and the control schools received no benefits. In future school research, study findings could be formulated as curriculum or activity recommendations tailormade to the participant schools and reporting to major stakeholders of schools to enhance response rates.

This study intended to examine the synergistic effect of integration of the Resilience Programme into the concept of HPS, with the aim of incorporating the merits of the Resiliency Programme into the components of social environment and community relationship of the HPS framework. Therefore, it is more appropriate to use non-HPS as control schools to demonstrate the effect size of this new HPS concept. Further studies would then involve four arms: HPS and non-HPS schools participating in the resilience intervention and HPS and

\section{What is already known on this subject}

- The Health Promoting School (HPS) embodies a holistic, whole school approach to personal and community health promotion and covers six key areas adapted from the World Health Organization (WHO).

- Guidelines are recognised as effective means to enhance social environment and community relationship, but no studies have evaluated whether resilience levels among the major school stakeholders can be enhanced by resilience-enhancing programmes.

\section{What this study adds}

- A newly designed resilience-promoting programme was shown to be effective to enhance resilience measures among secondary school teachers in HPS, with non-HPS as a control.

- It is recommended that this programme could play an important adjunctive role accompanying the implementation of HPS, and future initiatives may involve more emphasis on parent networking and school-family collaboration.

\section{Policy implications}

- The implementation of a tailormade resilience programme in secondary schools for Chinese populations is recommended among WHO Health Promoting Schools.

- Future initiatives may involve parent networking and schoolfamily collaboration in fostering an even more resilient school environment.
non-HPS schools not participating in the resilience intervention for further evaluation of programme effectiveness.

The present study supports the implementation of a tailormade resilience programme in secondary schools for Chinese populations. It is suggested that resilience-enhancing initiatives could involve parents to a greater extent both in networking with other parents and their participation in family-school collaborative activities in a school-based framework, like the Parent-Teachers Associations that have been commonly established in many Chinese school communities. The parents could then suggest further similar initiatives to be introduced for other school parents to improve family support in building resilience among schoolchildren. The Resilience Programme will undoubtedly help teachers to create a positive environment for the psychosocial development of young people. Future studies should be targeted towards evaluation of changes in resilience levels among students, which is under way. We believe a longer timeframe is needed for evaluation of resilient environments among students, as more time is needed to develop this social capital indirectly under the present programme where only teachers and parents were directly involved.

Acknowledgements: The authors would like to thank the Quality Education Fund of the Education and Manpower Bureau, Government of Hong Kong Special Administrative Region for support for this project.

Funding: Quality Education Fund, Education and Manpower Bureau, Hong Kong SAR Government.

Competing interests: None.

Ethics approval: Ethics approval was obtained from Survey and Behavioural Research Ethics Committee, Chinese University of Hong Kong.

\section{REFERENCES}

1. Lee A, Tsang KK, Healthy Schools Research Support Group. Youth Risk Behaviour in a Chinese Population: A territory wide Youth Risk Behavioural Surveillance in Hong Kong. Public Health 2004;118:88-95.

2. Lee A, et al. Health Crisis of Our New Generation: Surveillance on Youth Risk Behaviours. Centre for Health Education and Health Promotion, School of Public Health, The Chinese University of Hong Kong, 2002.

3. Lee A, Lee N, Tsang CKK, et al. Youth Risk Behaviour Survey, Hong Kong (2003/04). J Primary Care Health Promotion 2005; Special issue; 1-47.

4. Liu X, Tein JY, Zhao ZT, Sandler IN. Suicidality and correlates among rural adolescents of China. J Adolescent Health 2005;37:443-51.

5. Wear K. Promoting Mental, Emotional and Social Health: A Whole School Approach Routledge, London and New York, 2000.

6. Lee A, Lee SH, Tsang KK, et al. A comprehensive "Healthy Schools Programme" to promote school health: The Hong Kong experience in joining the efforts of Health and Education Sectors. J Epidemiol Community Health 2003;57:174-7.

7. Parsons C, Stears D, Thomas C. The health promoting school in Europe: Conceptualising and evaluating the change. Health Education J 1996;55:311-21.

8. Lee A, Cheng F, St Leger L. Evaluating Health Promoting Schools in Hong Kong: The Development of a Framework. Health Promotion Int 2005;20:177-86.

9. Lee A, St Leger L, Moon AS. Evaluating Health Promotion in Schools meeting the needs for education and health professionals: A case study of developing appropriate indictors and data collection methods in Hong Kong. Promotion Education 2005; 12:123-30.

10. Lee A, Cheng F, Fung Y, et al. Can Health Promoting Schools contribute to the better health and well being of young people: Hong Kong experience? J Epidemiol Community Health 2006;60:530-6.

11. Commonwealth Department of Health and Aged Care, 2000.

12. Rutter M. Resilience: some conceptual considerations. J Adolescent Health 1993; 14:626-31.

13. Rowe F, Stewart DE, Patterson C. "Promoting School Connectedness through Whole School Approaches" Health Education 2007;107:524-42.

14. Stewart D, Sun J, Patterson C, et al. Promoting and Building Resilience in Primary School Communities: Evidence from a Comprehensive 'Health Promoting School' Approach. Int J Mental Health Promotion 2004;6:26-33.

15. Rutter M. Psychosocial resilience and protective mechanisms Am J Orthopsychiatry 1987:57:316-31.

16. Fuller A. From Surviving to Thriving: Promoting Mental Health in Young People. Melbourne: ACER Press, 1998.

17. Ong AD, Bergeman CS, Bisconti TL, et al. Psychological Resilience, Positive Emotions, and Successful Adaptation to Stress in Later Life [Personality Processes and individual differences]. J Personality Social Psychol 2006;91:730-49. 
18. McGovern MA. Education and Care in Early Childhood. The OECD Observer 1993;164:21-3.

19. Stewart D, Sun J. How can we build resilience in Primary School Aged Children? The Importance of Social Support from Adults and Peers in family, School and Community Settings. Asia Pacific J Pub Health 2004;16:S37-41.

20. Lee A, Tsang KK, Lee SH, et al. A YRBS at Alternative High Schools and Main Stream School in Hong Kong. J School Health 2001;71:443-7.

21. Yip PS, Liu KY, Lam TH, et al. Suicidality among high school students in Hong Kong, SAR. Suicide Life-Threatening Behavior 2004;34:284-97.

22. Sun J, Stewart D. "Development of population based resilience measures in the primary school setting" Health Education 2007;107:575-99.

23. Sun J, Stewart D. How effective is the health-promoting school approach in building social capital in primary schools? Health Education 2007;107:556-74.
24. Gillham JE, Hamilton J, Freres DR, et al. Preventing Depression Among Early Adolescents in the Primary Care Setting: A Randomized Controlled Study of the Penn Resiliency Program. J Abnormal Child Psychol 2006;34:2003-119.

25. Gillham JE, Reivich KJ, Jaycox LH, et al. Preventing depressive symptoms in school children: Two year follow up. Psycholog Sci 1995;6:343-51.

26. Jaycox LH, Reivich KJ, Gillham J, et al. Prevention of depressive symptoms in school children. Behaviour Res Ther 1994;32:801-16.

27. Yu DL, Seligman MEP. Preventing depressive symptoms in Chinese children. Prev Treatment 2002;5. http://journals.apa.org/prevention/volume5/toc-may08-02.htm

28. Stewart D, Sun J. Resilience and depression in children: mental health promotion in primary schools in China. Int J Mental Health Promotion 2007;9:38-47.

29. Masten AS, Burt KB, Roisman $\mathrm{Gl}$, et al. Resources and resilience in the transition to adulthood: continuity and change. Dev Psychopathol 2004;16:1071-94. 